\title{
Volatility Regime and Equity Portfolio Return: Evidence from Europe
}

\author{
Chikashi Tsuji ${ }^{1}$ \\ ${ }^{1}$ Faculty of Economics, Chuo University, Tokyo, Japan \\ Correspondence: Chikashi Tsuji, Professor, Faculty of Economics, Chuo University, 742-1 Higashinakano, Hachioji-shi, \\ Tokyo 192-0393, Japan.
}

Received: February 1, 2018

Accepted: March 1, $2018 \quad$ Available online: March 3, 2018

doi:10.11114/aef.v5i3.3071

URL: https://doi.org/10.11114/aef.v5i3.3071

\begin{abstract}
This paper examines four European equity portfolios sorted by size, book-to-market (B/M) ratios, operating profitability, investment, and momentum by using Markov switching models with high and low volatility regimes. Our empirical analyses derive the following interesting findings. First, in four European equity portfolios, the smallest and the strongest momentum portfolio yields the highest return. In addition, the second smallest and the highest B/M portfolio, the second smallest and the highest operating profitability portfolio, and the second smallest and the second lowest investment portfolio also yield higher returns than the overall equity market in Europe. Further, our analyses using Markov switching models also reveal that for all the four European equity portfolios, the higher returns are obtained not in high volatility regimes but in low volatility regimes, and this evidence is against the assumption of risk-return trade off advocated in standard finance theory. Finally, our Markov switching analyses also suggest that for all the four European portfolios, staying probabilities in the same regimes are high and switching probabilities between two different regimes are generally low. In particular, staying probabilities in low volatility regimes are rather high, thus, all the four European equity portfolios yield high returns very stably by staying high return regimes.
\end{abstract}

Keywords: asset pricing, European equity portfolio, Markov switching model

\section{Introduction}

Performances of factor-sorted equity portfolios are of great concern for not only academic researchers but also practitioners in financial industries. In addition, regime switching approach to financial and economic time-series is also important analyzing methodology, which has long history in the fields of economics and finance (e.g., Hamilton, 1989; Filardo, 1994). In asset pricing literature, many factors for constructing profitable equity portfolios have been suggested (e.g., Fama and French, 1993, 2015), and to date, many empirical tests for the effectiveness of these factors also have been conducted. However, it is noted that those examinations are mainly for the US equities, thus, not enough research for the European equity portfolios has been implemented in the existing literature.

On the basis of the above motivation, this study tests the performances of equity portfolios sorted by several factors such as size, book-to-market (B/M) ratios, operating profitability, investment, and momentum by focusing on European equities by taking into consideration high and low volatility regimes. For this purpose, this study employs two-regime Markov switching models, and derives the following interesting findings for European equity portfolios.

First, in the four European equity portfolios we analyze in this paper, the smallest and the strongest momentum portfolio yields the highest return. In addition, the second smallest and the highest $\mathrm{B} / \mathrm{M}$ portfolio, the second smallest and the highest operating profitability portfolio, and the second smallest and the second lowest investment portfolio also yield higher returns than the overall equity market in Europe. These clearly indicate the effectiveness of constructing bivariate-sorted portfolios using European equities.

Further, our analyses using Markov switching models with high and low volatility regimes reveal that for all the four European equity portfolios, the higher returns are obtained not in high volatility regimes but in low volatility regimes. This is against the assumption of risk-return trade off suggested in standard finance theory. Finally, our Markov switching analyses also indicate that for all the four portfolios, staying probabilities in the same regimes are high and switching probabilities between two different regimes are generally low. In particular, staying probabilities in low volatility regimes are rather high, hence, all the four European equity portfolios yield high returns rather stably by staying their high return regimes. 
These some interesting findings are the contributions of this research. Regarding the rest of this article, in Section 2, recent related studies are reviewed; in Section 3, the data for our empirical study are explained; and in Section 4, our analyzing methodology is documented. After these, Section 5 explains our empirical results and Section 6 summarizes and concludes the paper.

\section{Literature Review}

This section briefly reviews recent empirical literature using regime switching approach. Recently, applying Markov switching method, Chourdakis et al. (2014) estimated the prices of regime-shift risk using the S\&P 500 option and its underlying equity index data. The results of their study suggested that the regime shifts of bull-to-bear and bear-to-crash carried substantial prices of risk. Salhi et al. (2016) also employed a regime switching model and estimated Value-at-Risk (VaR) using data of NYSE Euronext stocks from 2001 to 2011. The results of their study showed that the regime switching model employed in their analyses improved the predictive performance of VaR forecasting.

Bejaoui and Karaa (2016) attempted to better capture the bull and bear equity markets by extending the Markov switching model of Maheu and McCurdy (2000) to a multi-state model. Using stock index return data from the Tunis Stock Exchange and the extended regime switching model, they empirically defined the bull and bear equity markets in Tunisia in detail. Chatziantoniou et al. (2017) examined whether the shocks of UK monetary policy induce the UK housing and equity markets to remain at high-volatility environments. Using Markov switching modelling approach, they found that monetary policy shocks had predictive power for the UK equity market.

Using the US economic and equity market data and applying regime switching models, Hammerschmid and Lohre (2018) examined the US stock return predictability. Their regime switching approach empirically suggested that the regime factor was important in forecasting the US equity risk premium. It is again noted that equity portfolio return analysis for Europe by using regime switching approach was little seen in existing literature although for Japan, Tsuji (2012) conducted such analyses. Thus, as documented, this paper analyzes the relations of volatility regimes and equity portfolio returns in Europe in below sections.

Table 1. Average values of excess portfolio returns for European equities

\begin{tabular}{lccccc}
\hline & Low & 2 & 3 & 4 & High \\
\hline \multicolumn{2}{l}{ Panel A. Size-B/M portfolio } & & & & \\
\hline Small & -0.0283 & 0.4241 & 0.4990 & 0.6398 & 0.8078 \\
2 & 0.3358 & 0.5256 & 0.5857 & 0.7622 & $\mathbf{0 . 8 1 4 5}$ \\
3 & 0.3774 & 0.5960 & 0.5927 & 0.6018 & 0.8045 \\
4 & 0.5491 & 0.5754 & 0.6377 & 0.6229 & 0.7077 \\
Big & 0.3874 & 0.5667 & 0.6125 & 0.6876 & 0.5794 \\
\hline Panel B. Size-OP portfolio & & & & \\
\hline Small & 0.1922 & 0.7158 & 0.7958 & 0.9448 & 0.8258 \\
2 & 0.2972 & 0.6144 & 0.7535 & 0.8013 & $\mathbf{1 . 0 1 4 6}$ \\
3 & 0.3174 & 0.5953 & 0.7858 & 0.6775 & 0.8565 \\
4 & 0.2404 & 0.6020 & 0.7766 & 0.7510 & 0.7681 \\
Big & 0.1997 & 0.5956 & 0.5954 & 0.5050 & 0.6617 \\
\hline Panel C. Size-Inv portfolio & & & & \\
\hline Small & 0.5917 & 0.7570 & 0.7498 & 0.6969 & 0.2202 \\
2 & 0.6412 & $\mathbf{0 . 8 0 8 1}$ & 0.8021 & 0.6786 & 0.4267 \\
3 & 0.6938 & 0.7217 & 0.7362 & 0.5375 & 0.3548 \\
4 & 0.6926 & 0.6704 & 0.7022 & 0.6920 & 0.4498 \\
Big & 0.5976 & 0.6223 & 0.5380 & 0.4878 & 0.4926 \\
\hline Panel D. Size-Mom portfolio & & & & \\
\hline Small & -0.3170 & 0.3900 & 0.6433 & 1.0118 & $\mathbf{1 . 6 4 7 0}$ \\
2 & -0.0942 & 0.4476 & 0.7381 & 0.9826 & 1.4036 \\
3 & 0.1100 & 0.4659 & 0.6787 & 0.8626 & 1.1780 \\
4 & 0.1938 & 0.5657 & 0.6727 & 0.7999 & 1.0908 \\
Big & 0.2030 & 0.4923 & 0.6318 & 0.6550 & 0.7270 \\
\hline
\end{tabular}

Excess overall market return

0.5547

Notes: The sample period is from November 1990 to November 2017. The number of the observations is 325 . 


\section{Data}

This section explains the data used for this study. All data were supplied by Kenneth French and this study uses monthly percentage excess returns over risk-free rate as to four kinds of bivariate-sorted European equity portfolios. First is the excess return of the portfolio sorted by size and B/M ratios (henceforth 'Size-B/M portfolio'). Second is the excess return of the portfolio sorted by size and operating profitability (henceforth 'Size-OP portfolio').

Third is the excess return of the portfolio sorted by size and (corporate) investment (henceforth 'Size-Inv portfolio'), and fourth is that of the portfolio sorted by size and prior return (from 12-month prior to 2-month prior returns) (henceforth 'Size-Mom portfolio'). For the details of these portfolio constructions, see Fama and French (2015), and in this study, the sample period is from November 1990 to November 2017, and all returns are in US dollars. We also refer to the excess return of European overall equity market.

Table 1 shows the average values of excess returns of the above four kinds of European equity portfolios. As in Table 1, there are 25 Size-B/M portfolios, 25 Size-OP portfolios, 25 Size-Inv portfolios, and 25 Size-Mom portfolios. Further, as presented in bold, for Size-B/M portfolios, the highest average return is seen in the second smallest and the highest B/M portfolio (henceforth 'Size2-B/M5 portfolio') and for Size-OP portfolios, the highest average return is found in the second smallest and the highest operating profitability portfolio (henceforth 'Size2-OP5 portfolio').

Moreover, for Size-Inv portfolios, the highest average return is found in the second smallest and the second lowest investment portfolio (henceforth 'Size2-Inv2 portfolio') and for Size-Mom portfolios, the highest average return is seen in the smallest and the highest prior return portfolio (henceforth 'Size1-Mom5 portfolio'). Based on this evidence, the empirical study in this paper focuses on the above four higher return portfolios: Size2-B/M5 portfolio, Size2-OP5 portfolio, Size2-Inv2 portfolio, and Size1-Mom5 portfolio.

Table 2. Summary statistics of excess returns of higher return European equity portfolios

\begin{tabular}{lllll}
\hline & Size2-B/M5 portfolio & Size2-OP5 portfolio & Size2-Inv2 portfolio & Size1-Mom5 portfolio \\
\hline Mean & 0.8145 & 1.0146 & 0.8081 & 1.6470 \\
Median & 0.5700 & 1.0100 & 0.8000 & 1.9300 \\
Maximum & 16.9900 & 20.5300 & 13.8500 & 19.7600 \\
Minimum & -26.5700 & -26.0800 & -23.7200 & -22.5000 \\
Standard deviation & 5.2503 & 5.2412 & 4.7749 & 5.1794 \\
Skewness & -0.4556 & -0.5766 & -0.6124 & -0.4183 \\
Kurtosis & 5.5133 & 5.8636 & 5.6506 & 5.0768 \\
\hline
\end{tabular}

Notes: The sample period is from November 1990 to November 2017. The number of the observations is 325 .

Table 2 exhibits the descriptive statistics for the excess percentage returns over risk-free rate as to the four higher return European equity portfolios. As mean values exhibited in Table 2 indicate, in Europe, Size1-Mom5 portfolio shows the highest return of 1.65 percent per month. In addition, Size2-OP5 portfolio records the second highest return of 1.01 percent per month.

As in Table 1, since the average excess return of the European overall stock market is 0.55 percent per month, not only Size1-Mom5 portfolio and Size2-OP5 portfolio, but also Size2-B/M5 portfolio and Size2-Inv2 portfolio yield higher returns than overall equity market in Europe (The excess returns of Size2-B/M5 portfolio and Size2-Inv2 portfolio are both about 0.81 percent per month). Table 2 also indicates that all the four excess portfolio returns in Europe are negatively skewed and have fat-tailed distributions as all the returns show negative skewness values and larger kurtosis values than three of normal distributions.

\section{Methodology}

We next explain the model used for our empirical examinations. This study employs the following Markov switching model (1), which has high and low volatility regimes:

$$
r_{t}=\alpha(m)+\sigma(m) \epsilon_{t} .
$$

In equation (1), $r_{t}$ means the excess percentage return of one of the four European equity portfolios: Size2-B/M5 portfolio, Size2-OP5 portfolio, Size2-Inv2 portfolio, or Size1-Mom5 portfolio. In addition, $\alpha(m)$ denotes the intercept of the model, which depends on regime, $m$. Further, in the model (1), the disturbance term, $\epsilon_{t}$, is assumed to follow an independent and identically distributed (iid) standard normal distribution, and the standard deviation (volatility) in the regime $m$ is denoted by $\sigma(m)$. As documented, our model has two Markov switching regimes: high and low volatility regimes; and in this paper, all models are estimated by using the maximum likelihood method. 
Table 3. Estimation results of Markov switching models with high and low volatility regimes

\begin{tabular}{|c|c|c|c|c|c|}
\hline \multicolumn{3}{|c|}{ Panel A. Size2-B/M5 portfolio } & \multicolumn{3}{|c|}{ Panel B. Size2-OP5 portfolio } \\
\hline \multicolumn{3}{|c|}{ Low-volatility regime } & \multicolumn{3}{|c|}{ Low-volatility regime } \\
\hline & Estimates & $p$-value & & Estimates & $p$-value \\
\hline Constant $(\alpha)$ & $1.0455^{* * *}$ & 0.0001 & Constant $(\alpha)$ & $1.8013 * * *$ & 0.0000 \\
\hline $\ln \sigma$ & $1.4345 * * *$ & 0.0000 & $\ln \sigma$ & $1.2330 * * *$ & 0.0000 \\
\hline \multicolumn{3}{|c|}{ High-volatility regime } & \multicolumn{3}{|c|}{ High-volatility regime } \\
\hline & Estimates & $p$-value & & Estimates & $p$-value \\
\hline Constant $(\alpha)$ & -0.3601 & 0.7731 & Constant $(\alpha)$ & -0.5423 & 0.5154 \\
\hline $\ln \sigma$ & $2.1652 * * *$ & 0.0000 & $\ln \sigma$ & $2.0003 * * *$ & 0.0000 \\
\hline LL & -973.1940 & & $\mathrm{LL}$ & -969.9476 & \\
\hline \multicolumn{3}{|c|}{ Panel C. Size2-Inv2 portfolio } & \multicolumn{3}{|c|}{ Panel D. Size1-Mom5 portfolio } \\
\hline \multicolumn{3}{|c|}{ Low-volatility regime } & \multicolumn{3}{|c|}{ Low-volatility regime } \\
\hline & Estimates & $p$-value & & Estimates & $p$-value \\
\hline Constant $(\alpha)$ & $0.9654 * * *$ & 0.0001 & Constant $(\alpha)$ & $2.1455 * * *$ & 0.0000 \\
\hline $\ln \sigma$ & $1.3274 * * *$ & 0.0000 & $\ln \sigma$ & $1.3203 * * *$ & 0.0000 \\
\hline \multicolumn{3}{|c|}{ High-volatility regime } & \multicolumn{3}{|c|}{ High-volatility regime } \\
\hline & Estimates & $p$-value & & Estimates & $p$-value \\
\hline Constant $(\alpha)$ & 0.0080 & 0.9946 & Constant $(\alpha)$ & 0.3032 & 0.7689 \\
\hline $\ln \sigma$ & $2.0887 * * *$ & 0.0000 & $\ln \sigma$ & $2.0351 * * *$ & 0.0000 \\
\hline LL & -939.9159 & & LL & -975.0881 & \\
\hline
\end{tabular}

Notes: LL denotes the log-likelihood value and *** indicates the statistical significance at the $1 \%$ level. The sample period is from November 1990 to November 2017 and the number of the observations is 325 .

\section{Results}

This section documents our empirical results. For the four European equity portfolios, estimation results of our Markov switching models with high and low volatility regimes are shown in Table 3. First, from Panel A of this table, as the intercept values suggest, we understand that Size2-B/M5 portfolio exhibits positive excess return in low volatility regime, while this portfolio shows negative excess return in high volatility regime. Second, from Panel B of Table 3 , it is understood that Size2-OP5 portfolio also shows positive excess return in low volatility regime, while this portfolio also supplies negative excess return in high volatility regime.

Further, as Panel C of Table 3 shows, Size2-Inv2 portfolio again presents higher positive excess return in low volatility regime, while this portfolio supplies almost no excess return in high volatility regime. Finally, as Panel D of Table 3 indicates, Size1-Mom5 portfolio again shows higher positive excess return in low volatility regime, while the portfolio supplies low excess return in high volatility regime.

As above, our results derived from the Markov switching models are very similar and clear for all the four equity portfolios. To sum up, from the regime switching perspective, our results supply little evidence that supports the risk-return trade off, and this is against the standard finance theory. That is, our evidence shows that for European equity portfolios, higher returns are obtained not in high volatility regime but in low volatility regime.

Table 4. Transition probabilities from Markov switching models

\begin{tabular}{lllll}
\hline & Low to low & Low to high & High to low & High to high \\
\hline Size2-B/M5 portfolio & 0.9961 & 0.0039 & 0.0245 & 0.9755 \\
Size2-OP5 portfolio & 0.9599 & 0.0401 & 0.0800 & 0.9200 \\
Size2-Inv2 portfolio & 0.9961 & 0.0039 & 0.0245 & 0.9755 \\
Size1-Mom5 portfolio & 0.9532 & 0.0468 & 0.1290 & 0.8710 \\
\hline
\end{tabular}

Notes: In this table, 'Low to low' means the staying probabilities in low volatility regime, 'Low to high' means the transition probabilities from low volatility regime to high volatility regime, 'High to low' means the transition probabilities from high volatility regime to low volatility regime, and 'High to high' means the staying probabilities in high volatility regime. The sample period is from November 1990 to November 2017 and the number of the observations is 325 . 
Panel A. Size2-B/M5 portfolio

Low-volatility regime

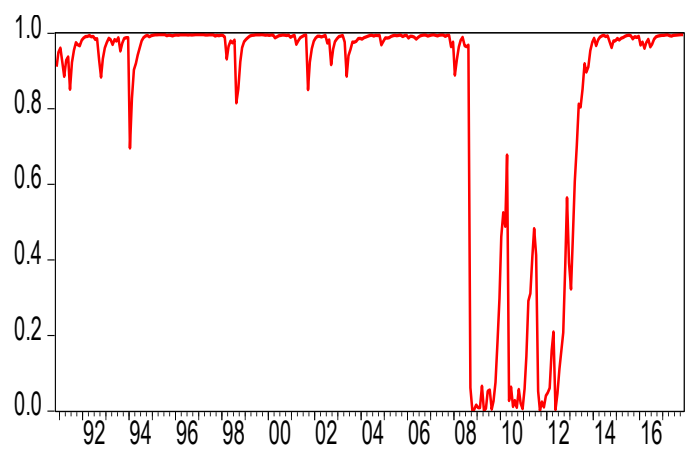

High-volatility regime

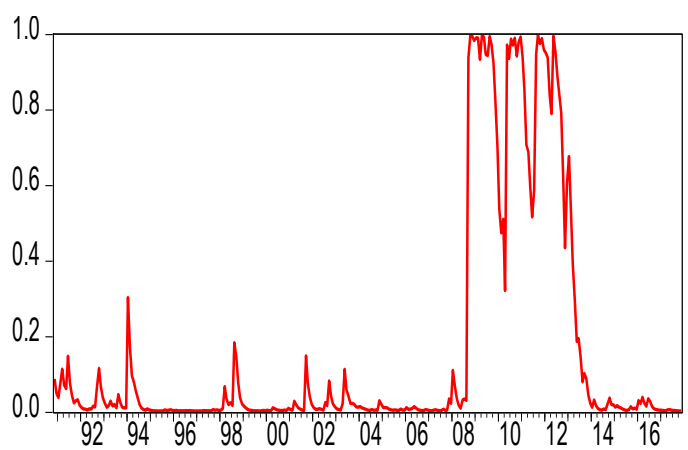

Panel C. Size2-Inv2 portfolio

Low-volatility regime

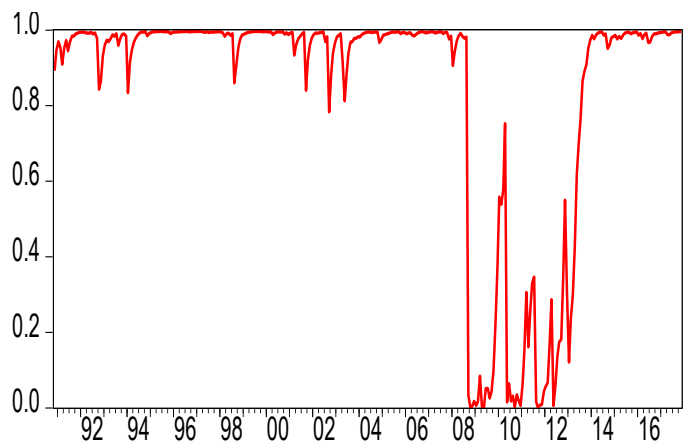

High-volatility regime

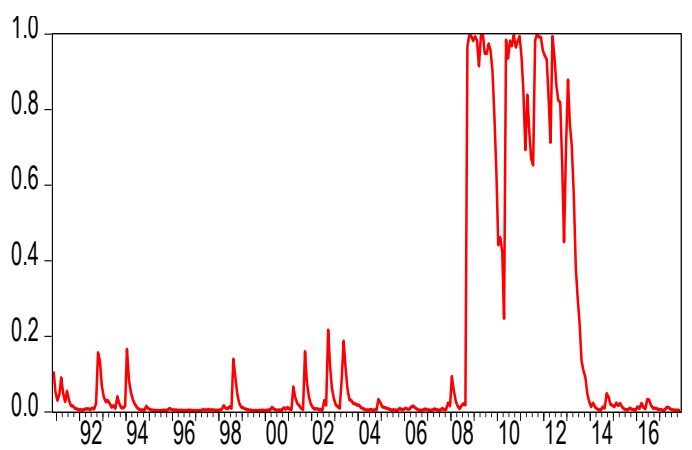

Panel B. Size2-OP5 portfolio

Low-volatility regime

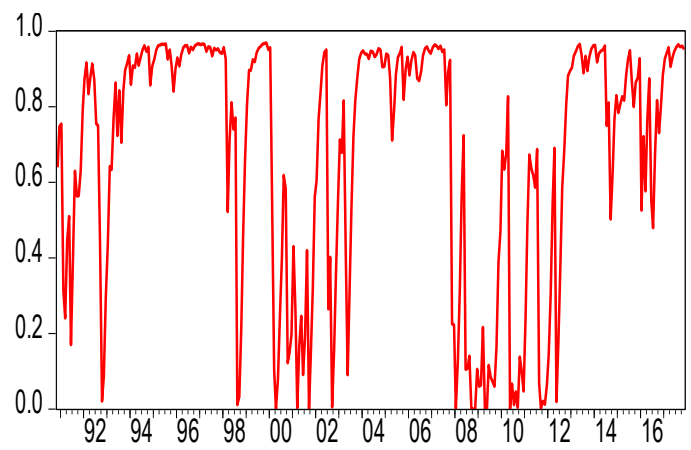

High-volatility regime

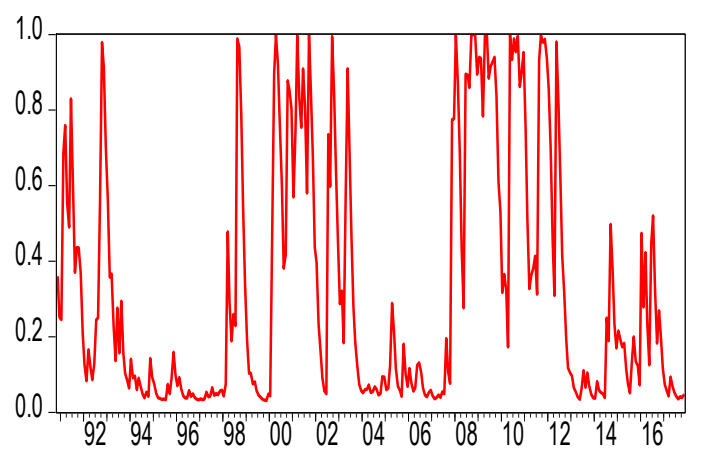

Panel D. Size1-Mom5 portfolio

Low-volatility regime

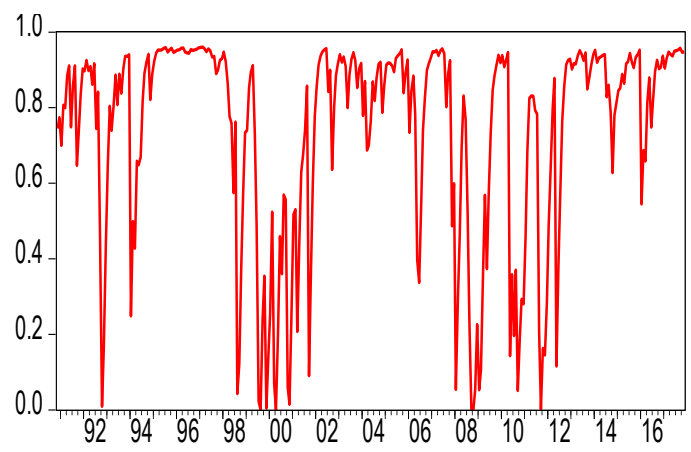

High-volatility regime

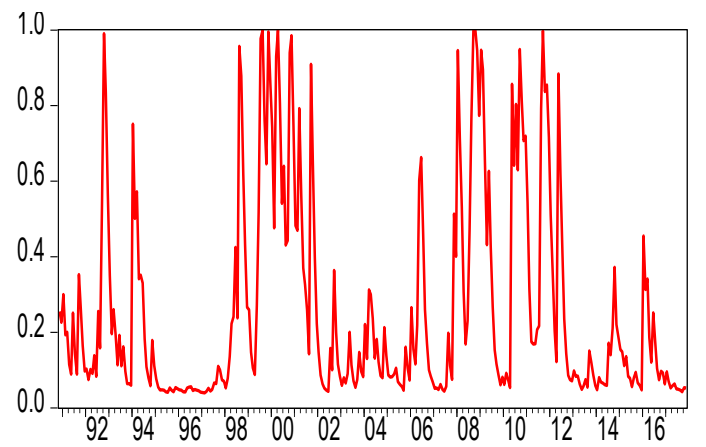

Figure 1. Markov switching regime probabilities: High and low volatility regimes 
Moreover, Figure 1 shows the Markov switching high and low volatility regime probabilities for the four European equity portfolios, which are derived from model (1). Panels A and C of this figure suggest that Size2-B/M5 portfolio and Size2-Inv2 portfolio stay in high volatility regime around the Lehman crisis and European debt crisis periods. Panels B and D of Figure 1 also indicate that Size2-OP5 portfolio and Size1-Mom5 portfolio stay in high volatility regime not only around the Lehman collapse and European debt crisis periods, but also around 1998 and 2000 to 2002, during which there were volatility increasing events of Russian crisis in 1998 and the US terrorist attack in 2001. That is, our empirical results and graphical analyses suggest that excluding such higher volatility periods, all the four European equity portfolios yield high returns for international investors.

Furthermore, Table 4 shows the transition probabilities between two regimes for the four European portfolio excess returns, which are also derived from our Markov switching models. In this table, 'Low to low' means the staying probabilities in low volatility regime, 'Low to high' means the transition probabilities from low volatility regime to high volatility regime, 'High to low' means the transition probabilities from high volatility regime to low volatility regime, and 'High to high' means the staying probabilities in high volatility regime. Table 4 suggests that for all the four portfolios, staying probabilities in the same regimes are high and switching probabilities between two different regimes are generally low. In particular, staying probabilities in low volatility regimes are rather high, thus, all the four European equity portfolios yield high returns very stably by staying high-return regimes.

\section{Conclusions}

This paper investigated the profitability of the four European equity portfolios of the second smallest and the highest $\mathrm{B} / \mathrm{M}$ portfolio, the second smallest and the highest operating profitability portfolio, the second smallest and the second lowest investment portfolio, and the smallest and the highest prior return (momentum) portfolio. Using the Markov switching models with high and low volatility regimes, we derived the following interesting findings.

(1) First, in the four European equity portfolios, the smallest and the strongest momentum portfolio exhibited the highest return. While excess overall equity market return in Europe was 0.55 percent per month, the smallest and the strongest momentum portfolio demonstrated the average excess return of 1.65 percent per month in Europe.

(2) Second, the second smallest and the highest $\mathrm{B} / \mathrm{M}$ portfolio, the second smallest and the highest operating profitability portfolio, and the second smallest and the second lowest investment portfolio also exhibited higher excess returns than the overall equity market in Europe. These clearly indicate the effectiveness of constructing bivariate-sorted portfolios using European equities.

(3) Furthermore, our analyses using Markov switching models with high and low volatility regimes revealed that for all the four European equity portfolios, the higher returns were obtained not in high volatility regimes but in low volatility regimes. It is emphasized that this is against the assumption of risk-return trade off suggested in standard finance theory.

(4) Finally, our Markov switching analyses indicated that for all the four European equity portfolios, staying probabilities in the same regimes were high and switching probabilities between two different regimes were generally low. In particular, staying probabilities in low volatility regimes were very high, hence, all the four European equity portfolios analyzed in this paper earned high returns stably by staying their high-return regimes.

In fact, there exist different types of models that allow for analyzing regime changes of financial and economic time-series data, and the Markov switching model is one of those models. It is pointed out that the Markov switching model is very delicate and difficult model to derive reasonable or expected results. However, as above, in our cases, applications of Markov switching models to European equity portfolio excess returns were highly successful. We note again that our results, which were against the risk-return trade off suggested by standard finance theory, were very clear in all the four cases for European equity portfolios analyzed in this paper.

Hence, in the case where data and the model are well fitted, applying regime switching models to financial and economic time-series data is expected to be effective and useful for deriving interesting evidence. Therefore, extended or new empirical research by applying similar models to different financial and/or economic data shall be meaningful, and it is one of our future works.

\section{Acknowledgements}

The author firstly appreciates this journal for its kind repeated article invitation. The author also greatly appreciates Nikki Gibbs for her kind editorial assistance to this paper. In addition, the author thanks an editor of this journal and an anonymous reviewer for their constructive and supportive comments on this paper. Furthermore, the author also appreciates the Japan Society for the Promotion of Science Grant-in-Aid for Scientific Research and the Chuo University Personal Research Grant for their generous financial assistance to my research. Finally, I deeply thank all the Editors of this journal for their kind attention to my paper. 


\section{References}

Bejaoui, A., \& Karaa, A. (2016). Revisiting the bull and bear markets notions in the Tunisian stock market: New evidence from multi-state duration-dependence Markov-switching models. Economic Modelling, 59, 529-545. https://doi.org/10.1016/j.econmod.2016.08.018

Chatziantoniou, I., Filis, G., \& Floros, C. (2017). Asset prices regime-switching and the role of inflation targeting monetary policy. Global Finance Journal, 32, 97-112. https://doi.org/10.1016/j.gfj.2015.12.002

Chourdakis, K., Dendramis, Y., \& Tzavalis, E. (2014). Are regime-shift sources of risk priced in the market? Journal of Empirical Finance, 28, 151-170. https://doi.org/10.1016/j.jempfin.2014.06.004

Fama, E. F., \& French, K. R. (1993). Common risk factors in the returns on stocks and bonds. Journal of Financial Economics, 33, 3-56. https://doi.org/10.1016/0304-405X(93)90023-5

Fama, E. F., \& French, K. R. (2015). A five-factor asset pricing model. Journal of Financial Economics, 116, 1-22. https://doi.org/10.1016/j.jfineco.2014.10.010

Filardo, A. J. (1994). Business-cycle phases and their transitional dynamics. Journal of Business \& Economic Statistics, 12, 299-308. https://doi.org/10.1080/07350015.1994.10524545

Hamilton, J. D. (1989). A new approach to the economic analysis of nonstationary time series and the business cycle. Econometrica, 57, 357-384. https://doi.org/10.2307/1912559

Hammerschmid, R., \& Lohre, H. (2018). Regime shifts and stock return predictability. International Review of Economics and Finance, forthcoming. https://doi.org/10.1016/j.iref.2017.10.021

Maheu, J. M., \& McCurdy, T. H. (2000). Identifying bull and bear markets in stock returns. Journal of Business \& Economic Statistics, 18, 100-112. https://doi.org/10.2307/1392140

Salhi, K., Deaconu, M., Lejay, A., Champagnat, N., \& Navet, N. (2016). Regime switching model for financial data: Empirical risk analysis. Physica A, 461, 148-157. https://doi.org/10.1016/j.physa.2016.05.002

Tsuji, C. (2012). Positive return premia in Japan. Quantitative Finance, 12, 345-367. https://doi.org/10.1080/14697688.2010.541485

\section{Copyrights}

Copyright for this article is retained by the author(s), with first publication rights granted to the journal.

This is an open-access article distributed under the terms and conditions of the Creative Commons Attribution license which permits unrestricted use, distribution, and reproduction in any medium, provided the original work is properly cited. 